UCRL CONF 204294

\title{
Detection of Uncertain Seismic Signals
}

\author{
David Harris \\ Lawrence Livermore National Laboratory \\ 147th Meeting of the Acoustical Society of America: \\ Inverse Problems in Seismic Processing \\ May 25, 2004
}

This work was performed under the auspices of the U.S. Department of Energy by the University of California, Lawrence Livermore National

Laboratory, under Contract No. W-7405-Eng-48. 
This document was prepared as an account of work sponsored by an agency of the United States Government. Neither the United States Government nor the University of California nor any of their employees, makes any warranty, express or implied, or assumes any legal liability or responsibility for the accuracy, completeness, or usefulness of any information, apparatus, product, or process disclosed, or represents that its use would not infringe privately owned rights. Reference herein to any specific commercial product, process, or service by trade name, trademark, manufacturer, or otherwise, does not necessarily constitute or imply its endorsement, recommendation, or favoring by the United States Government or the University of California. The views and opinions of authors expressed herein do not necessarily state or reflect those of the United States Government or the University of California, and shall not be used for advertising or product endorsement purposes. 
Current seismic detection practice is concentrated at the extremes of a spectrum of possibilities

Signal

Knowledge of the Signal

Signal

Unknown

Known

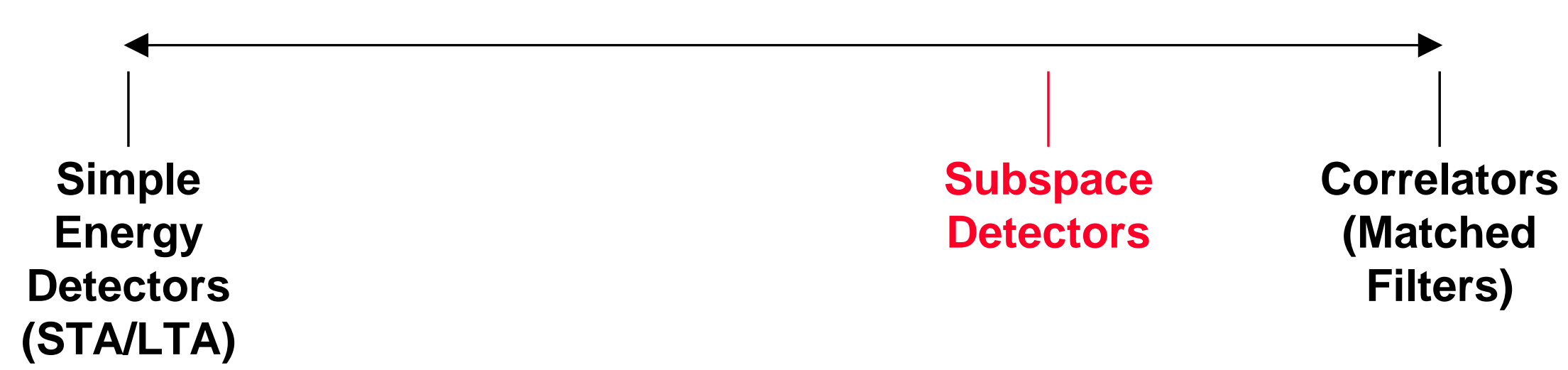

- Correlation detectors are very sensitive

- Energy detectors are broadly applicable

- An intermediate option is desirable 


\section{Subspace detectors add an uncertain signal model}

to the usual formulation of the detection problem

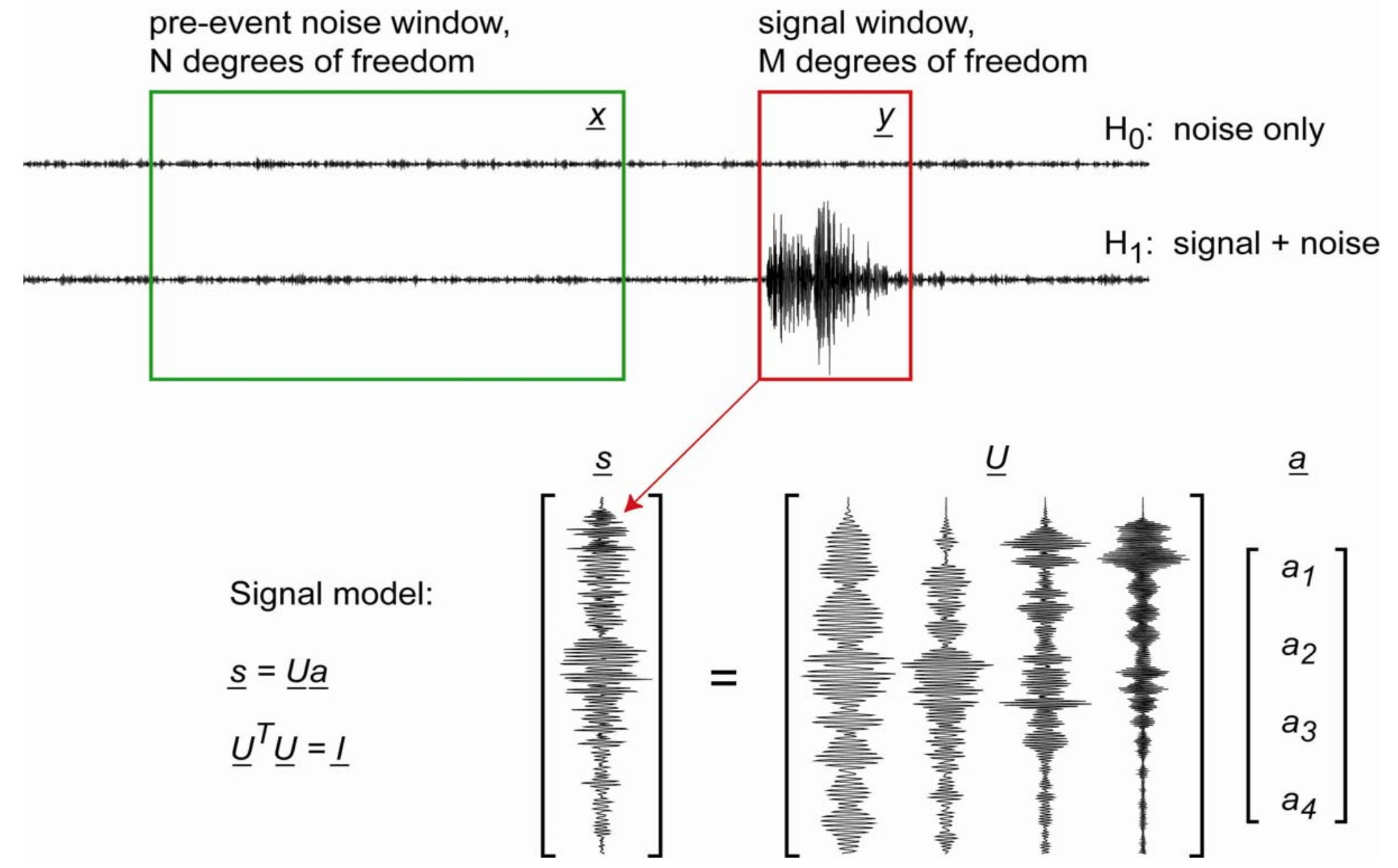


A single detection framework can span detectors ranging from simple energy detectors to correlators

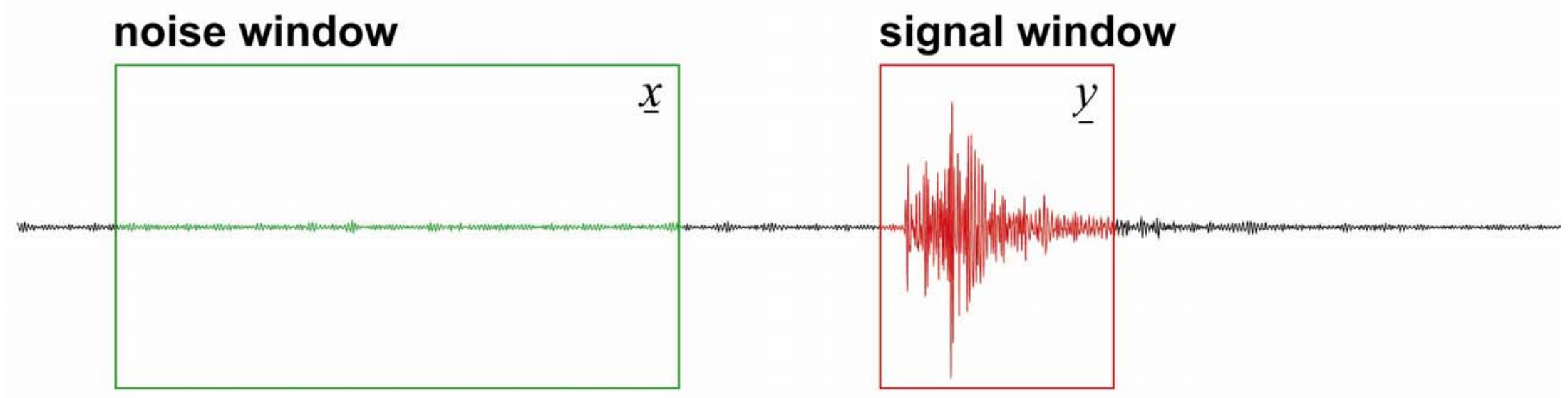

\section{detection rule}

$$
\begin{aligned}
\frac{y_{p}^{T} y_{p}}{\underline{x}^{T} \underline{x}+\underline{y}^{T} y-\underline{y}_{p}^{T} y_{p}} & \gtrless \text { threshold } \\
\underline{y}_{p} & =\underline{U}^{T} \underline{y}
\end{aligned}
$$

energy detector

$$
\underline{U}=\underline{I} \quad z=\frac{\underline{y}^{T} \underline{y}}{\underline{x}^{T} \underline{x}}
$$

subspace detector

$$
\underline{x}^{T} \underline{x} \rightarrow 0
$$




\section{Processing sequence for detecting swarm events}

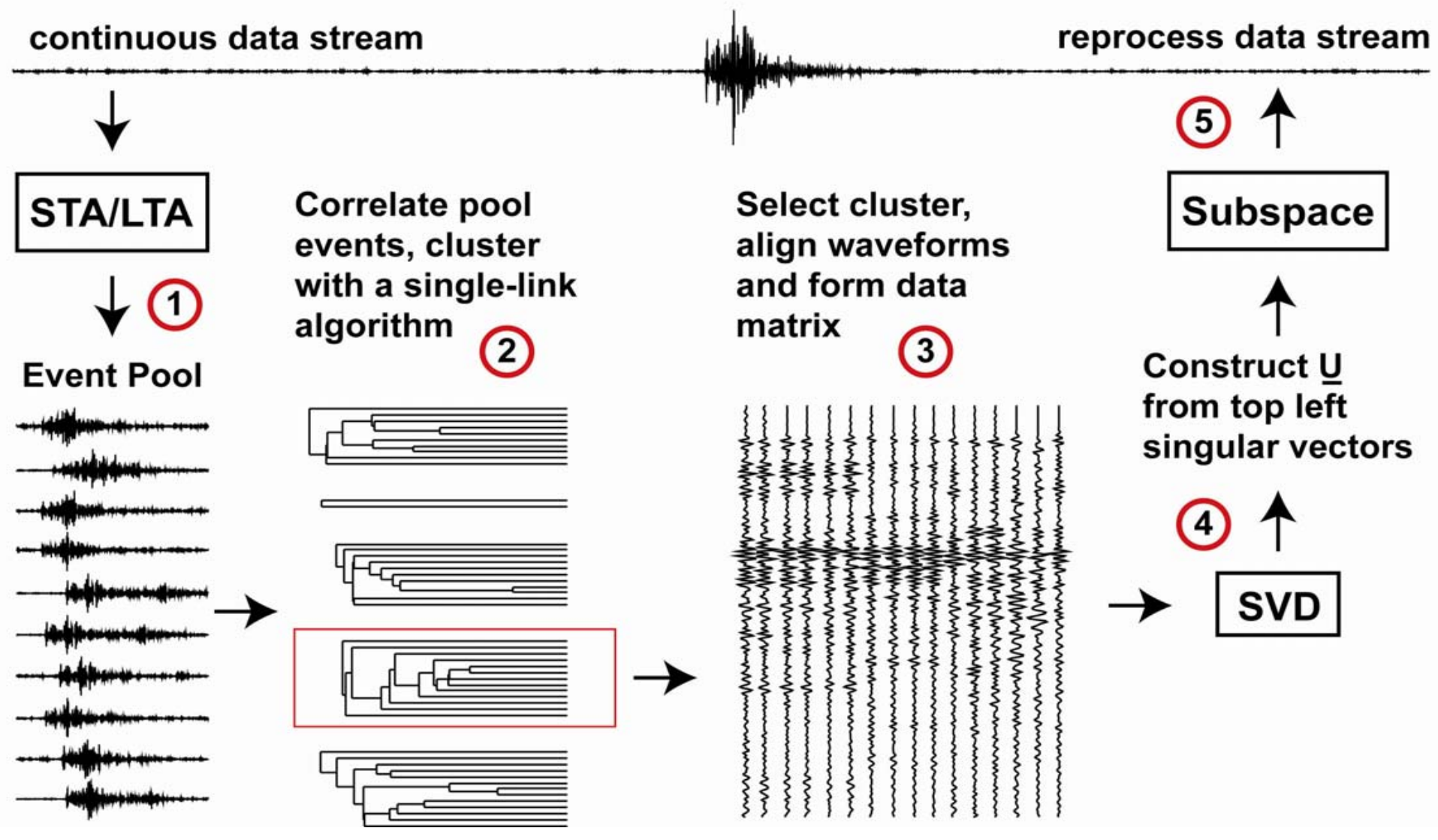




\section{Example: Nov-Dec 2002 San Ramon, California Swarm}
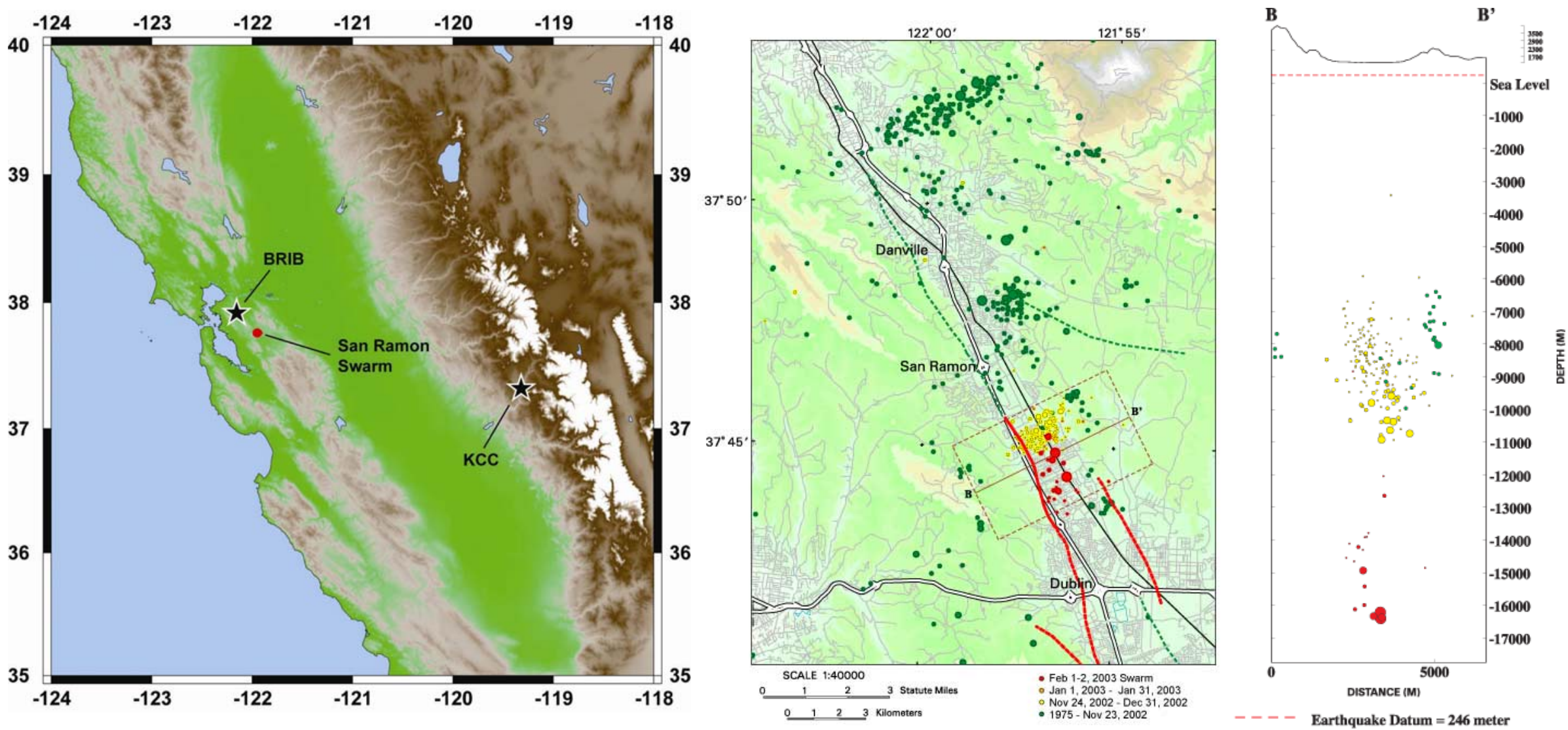

Data credit: NCEDC, Berkeley Seismological Laboratory 


\section{Detector dimension and threshold should be set to}

assure detection of the design events

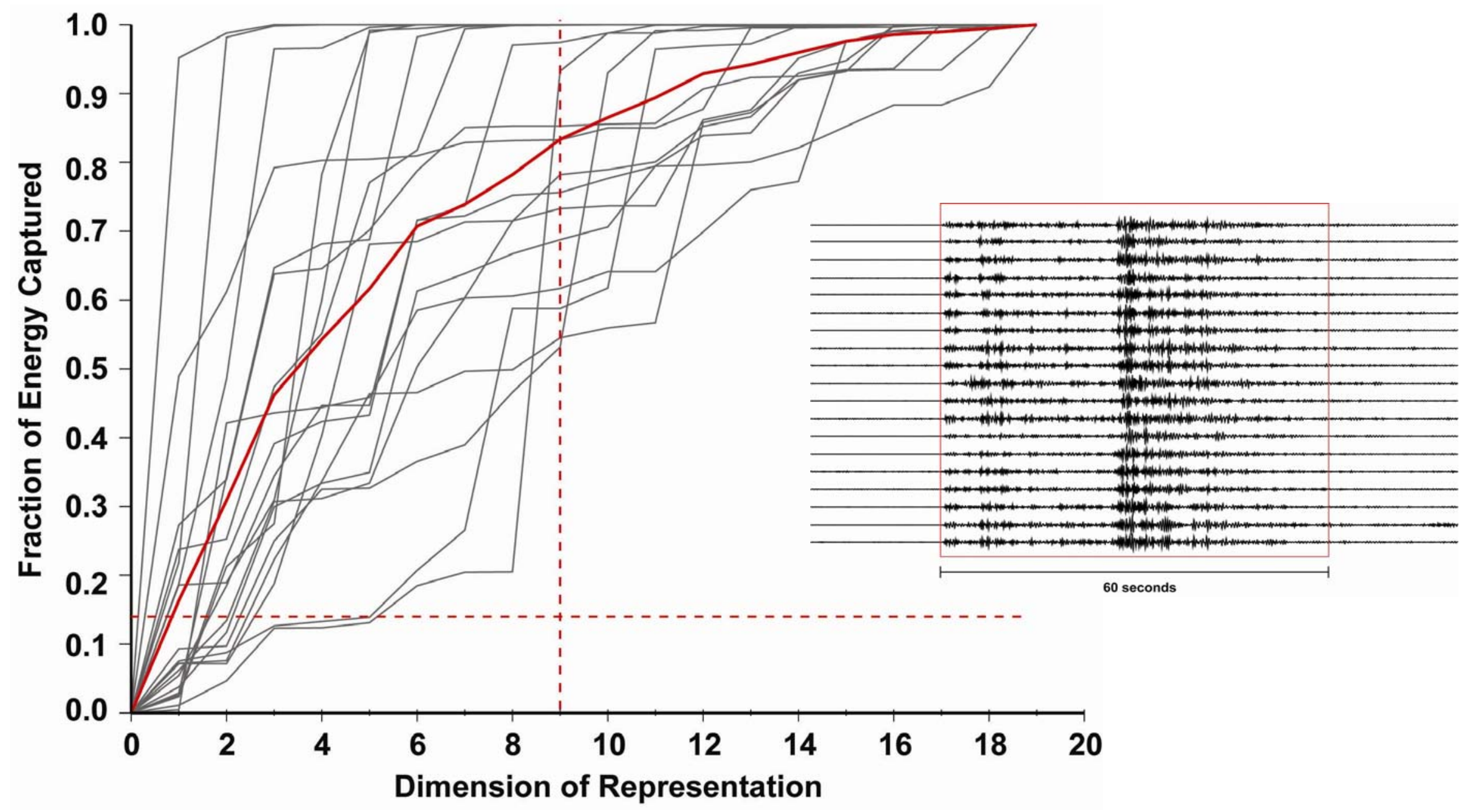


The subspace dimension is chosen to optimize the probability of detection

- Maximize $P_{D}$ at a fixed $P_{F}$

- Minimize cost of computation where $P_{D}$ is essentially constant

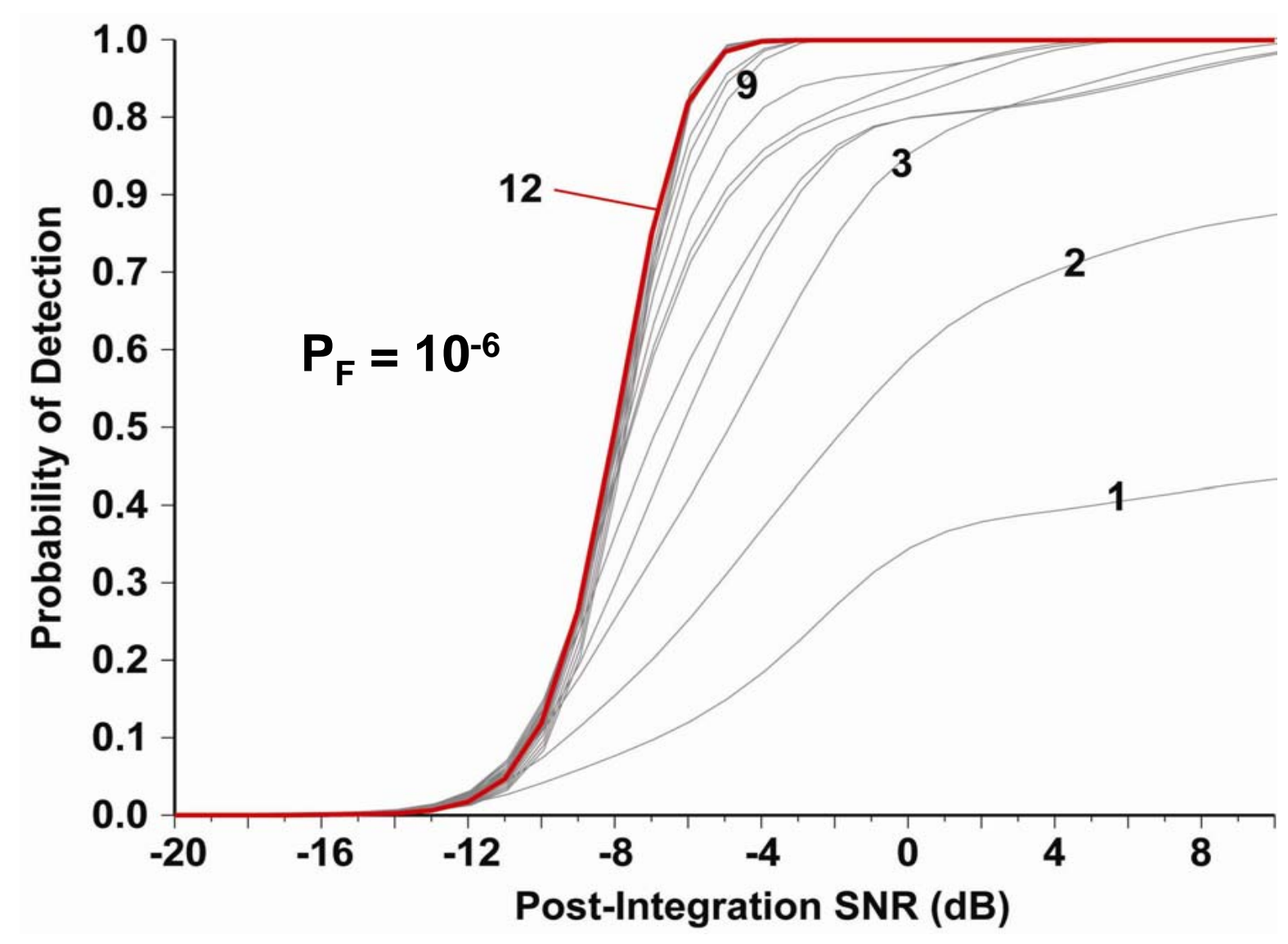




\section{Subspace detectors have an efficjent}

implementation

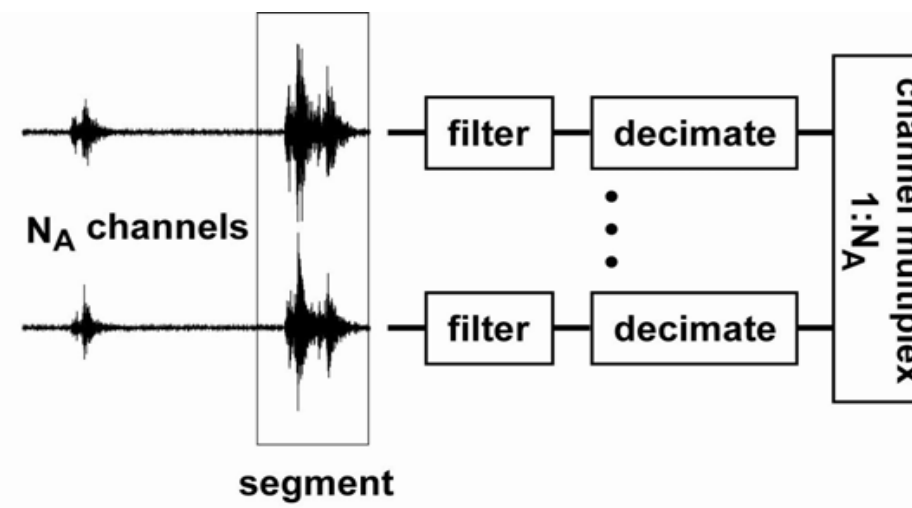

A 10-dimension, 3-channel Java implementation is more than 100 times faster than real time @ 20 sps

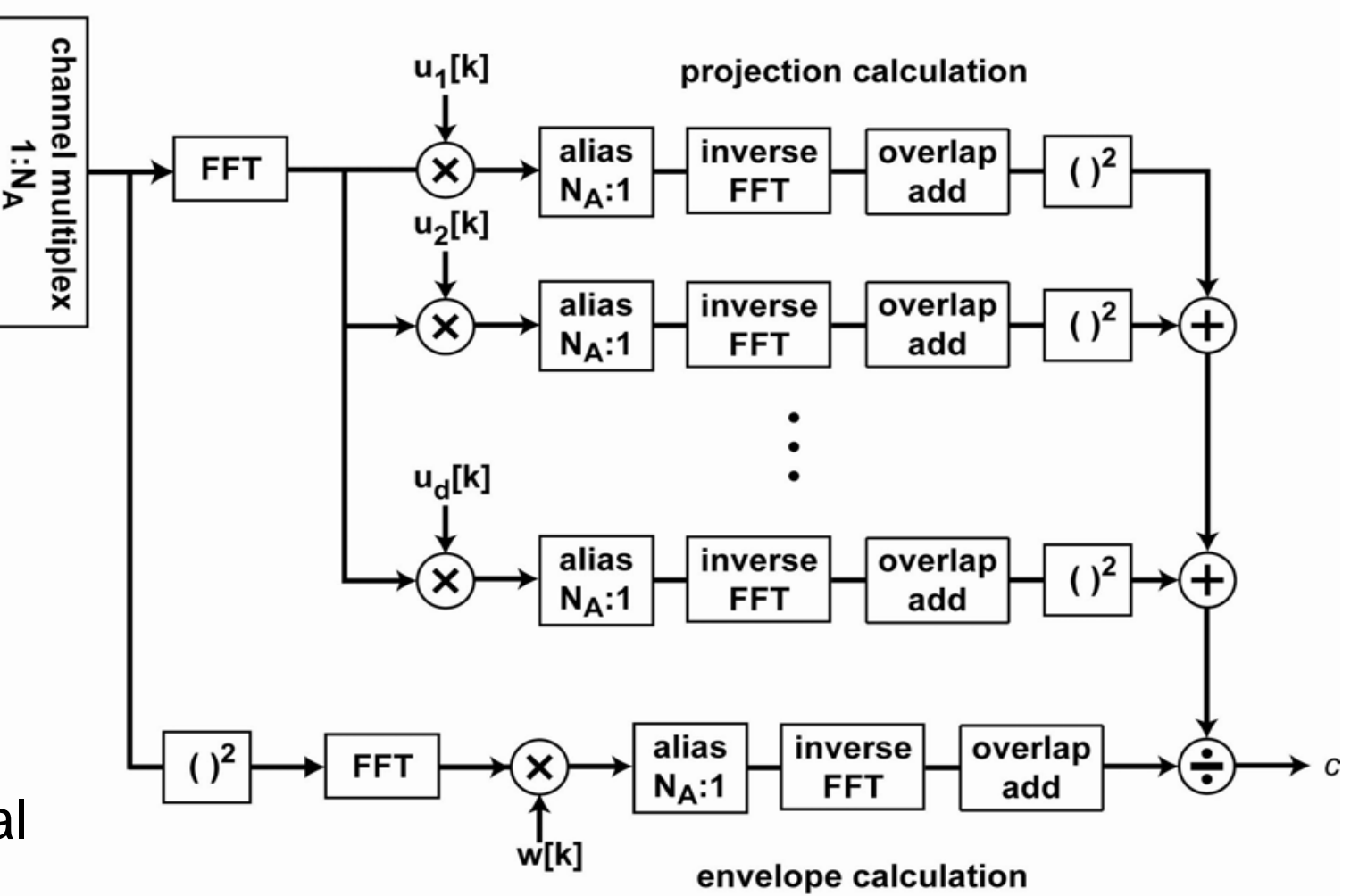


The subspace detector has a higher noise floor, but significantly better processing gain

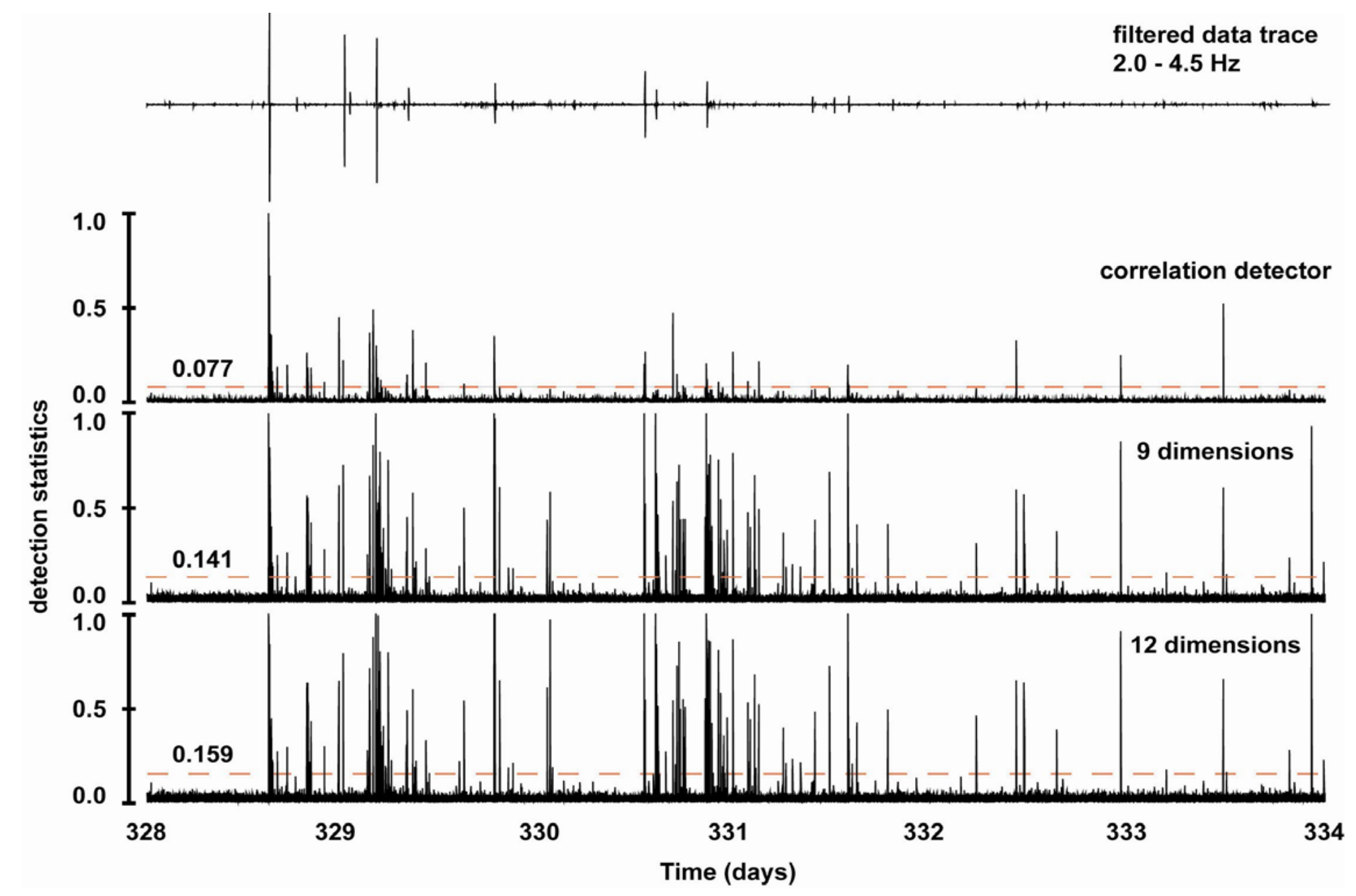

Lawrence Livermore National Laboratory, Dave Harris - 5/20/2004 - 10 


\section{The subspace detector captures twice as many}

events as the correlator at the same theoretical $P_{F}$
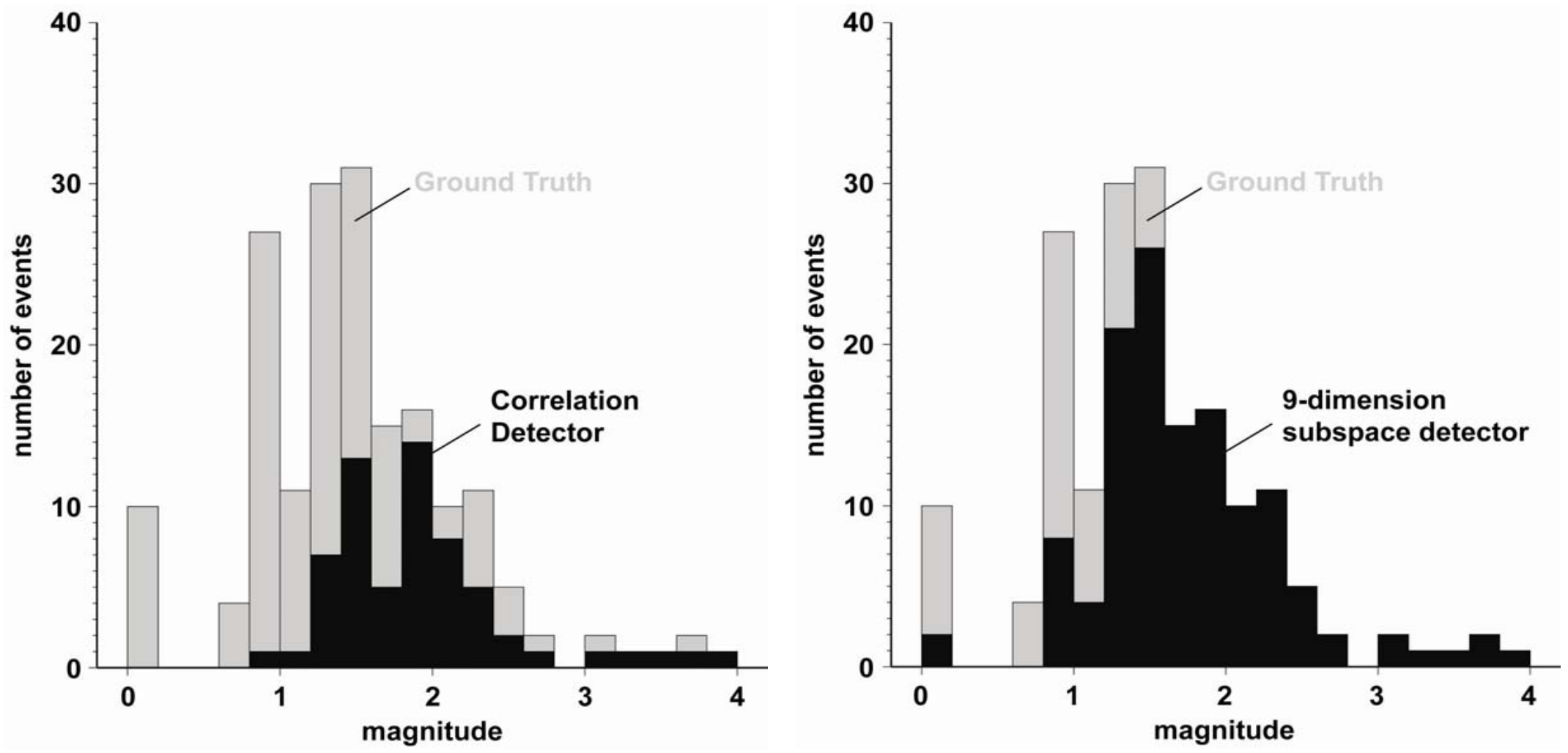

Detection threshold: $\sim 1.5 @ 240$ km 


\section{The subspace detector has broader coverage in the}

source region

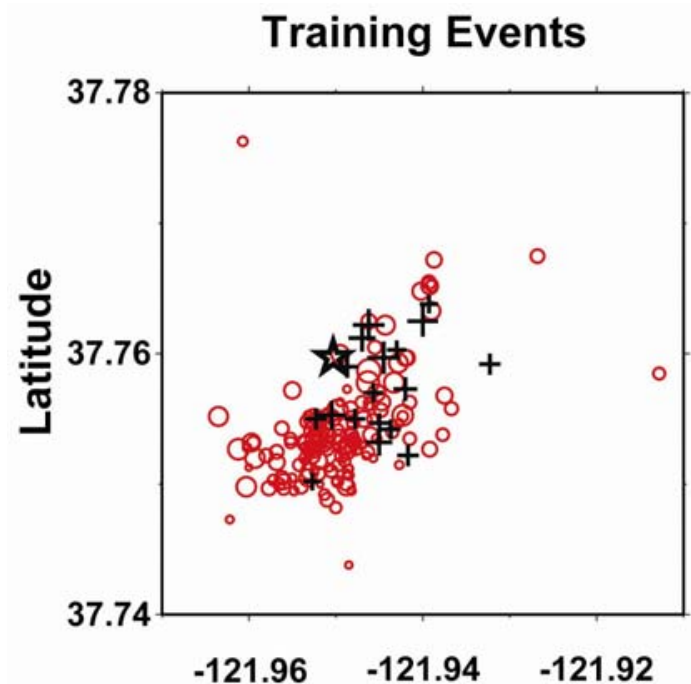

Correlation Detections
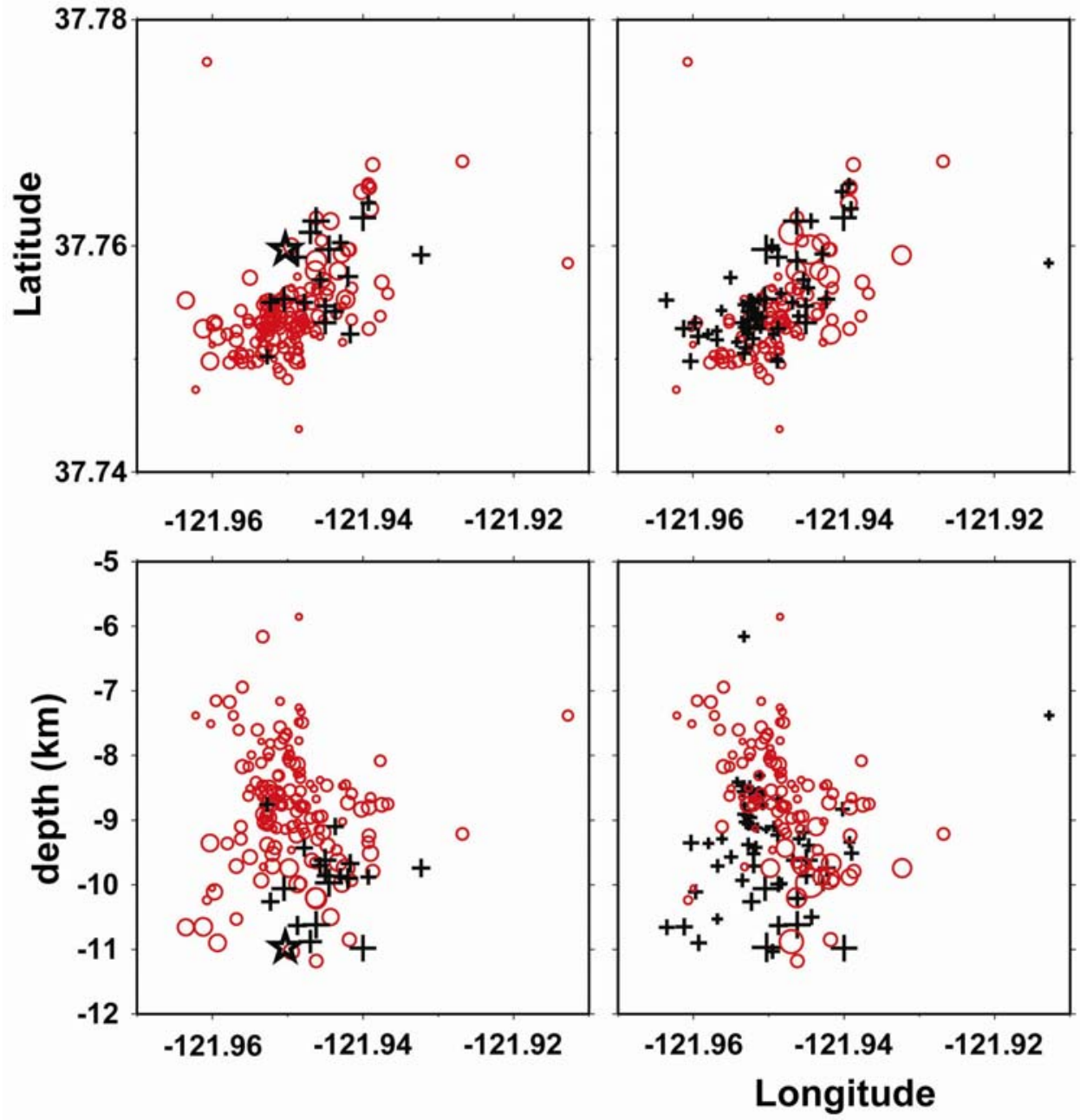

Subspace Detections
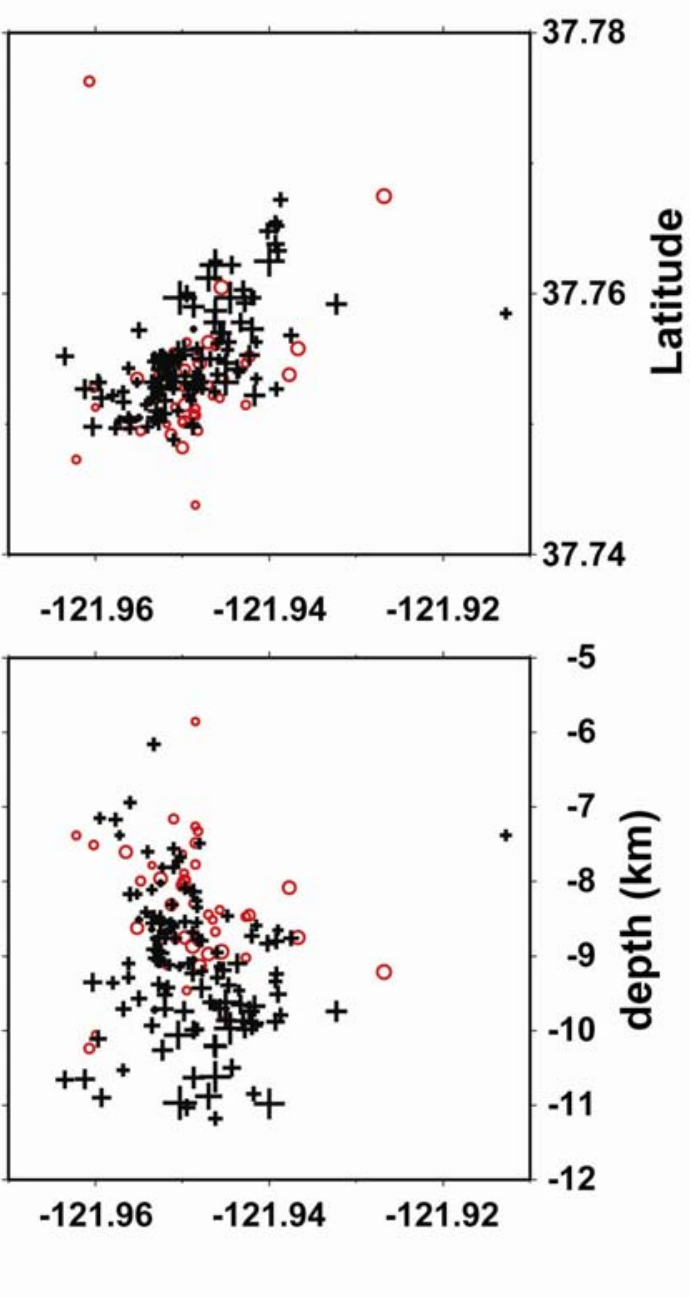


\section{Under plausibly achievable circumstances, subspace}

detectors may provide as much gain as arrays
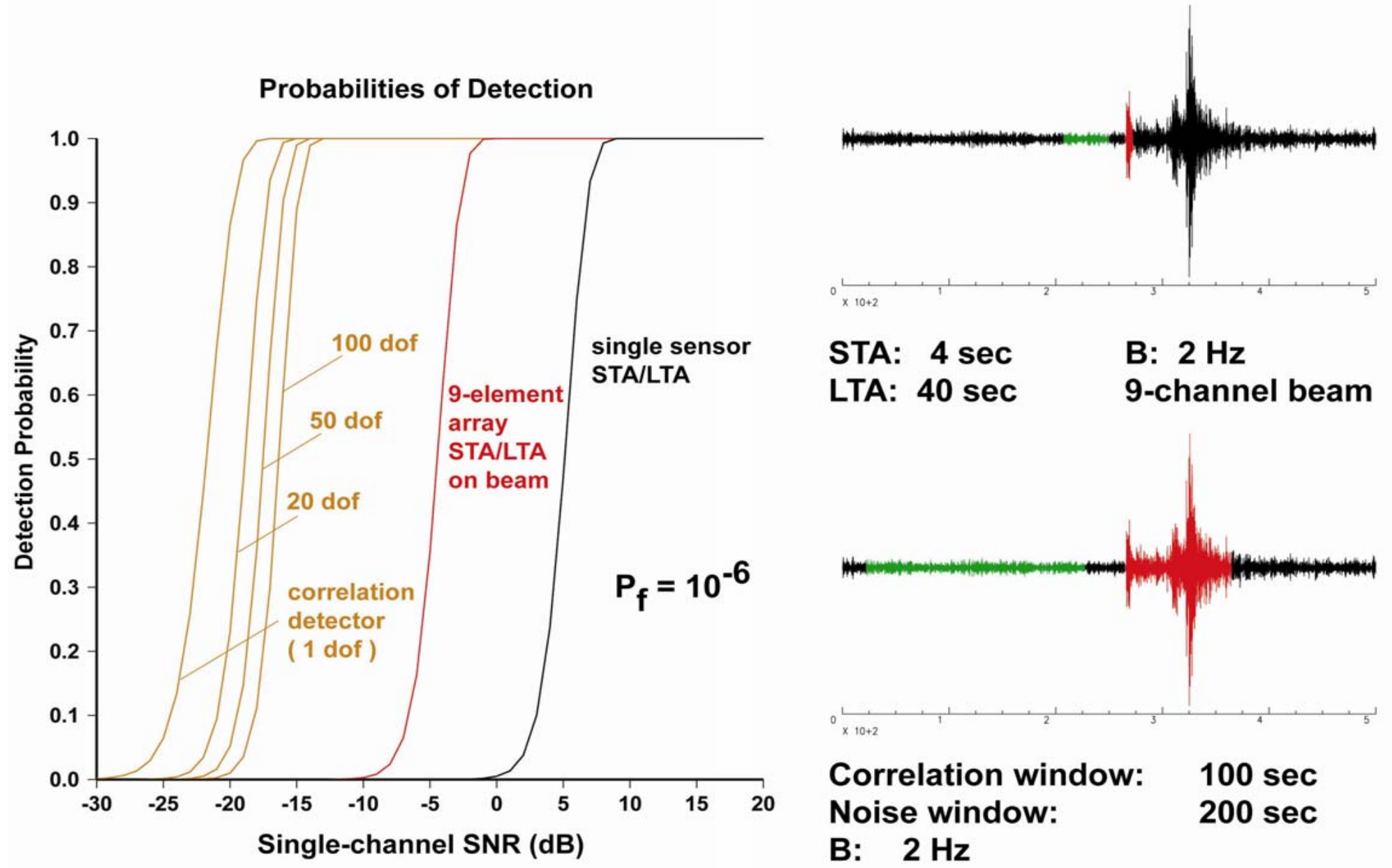

STA: $4 \mathrm{sec} \quad$ B: $2 \mathrm{~Hz}$

LTA: 40 sec 9-channel beam

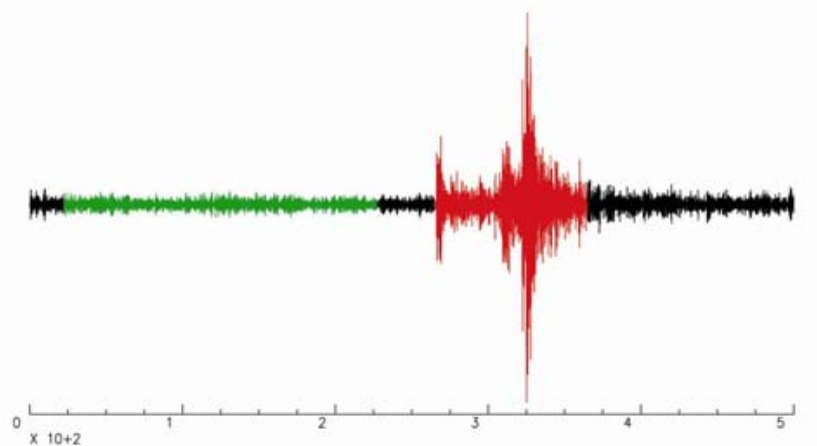

Correlation window: $100 \mathrm{sec}$ Noise window:

$200 \mathrm{sec}$

B: $2 \mathrm{~Hz}$

9 channels 


\section{Summary: subspace detectors are a promising approach}

to detecting uncertain seismic signals

- They allow systematic exploitation of partial information about the signal

- A rigorous statistical design approach is available

- There is the theoretical prospect of detectors "dialable" from simple energy detectors to correlators

- Good performance has been demonstrated on an earthquake swarm 